\title{
Integrating Assistive Technology Into an Outcome-Driven Model of Service Delivery
}

\author{
Toby Long, PhD, PT; Larke Huang, PhD; \\ Michelle Woodbridge, PhD; Maria Woolverton, BA; \\ Jean Minkel, MA, PT
}

\begin{abstract}
Infants and toddlers with disabilities and special health care needs (SHCN) have complex habilitative and health care needs requiring multiple services throughout their lives. Providers of services to children underutilize assistive technology (AT) and AT services. This underutilization has a significant impact on how well and how easily the children are integrated in home, school, and community activities. The literature indicates that AT is appropriate when the device (a) is related to specific and clearly defined goals that are meaningful to the child and family; (b) takes into consideration practical constraints, such as the environment and funding resources; and (c) results in the child achieving desired outcomes. Using an outcome-driven model this article outlines a 10-step framework that can be used by service providers to guide them in determining the fit between the child's needs and AT and/or AT services. Components of the framework and critical information needed for decision-making at each step will be discussed. A family-centered, interdisciplinary team philosophy is promoted. Key words: assistive technology, assistive technology services, decision-making, system of care, The Consortium Model
\end{abstract}

$\mathbf{I}$

NFANTS and toddlers with disabilities and special health care needs (SHCN) have complex habilitative and health care needs often requiring a similarly complex array of services throughout their lives. Rehabilitative services and early intervention are increasingly available to children with disabilities and

From the Center for Child and Human Development, Georgetown University, Washington, DC (Drs Long and Huang and Ms Woolverton); Office of Campus Outreach Initiatives, the University of California, Santa Barbara, Calif (Dr Woodbridge); and the Minkel Consulting, Windsor, NY (Ms Minkel).

This work was supported by the National Institute on Disability and Rehabilitation Research of the US Department of Education under grant number H133B001200 to the Consortium for Children and Youth with Disabilities and Special Health Care Needs.

Corresponding author: Toby Long, PhD, PT, Center for Child and Human Development, Georgetown University, 3307 M St. NW, Suite 401, Washington, DC 20007 (e-mail: longt@georgetown.edu). assistive technology (AT) is a critical component of this service array.

In spite of significant advances in AT and AT services, these interventions remain underutilized and poorly integrated into rehabilitation plans for children with special health care needs. The objectives of this article are to first highlight some of the barriers to more effective utilization of AT and then provide a clinical decision-making framework that may help providers incorporate AT and AT services into a system of care for young children with disabilities.

While the number of infants and toddlers using AT has increased by approximately $60 \%$ since 1992, this is just a fraction of the number of children receiving early intervention services. Throughout the country only about $7 \%$ of the children receiving early intervention services also receive AT or AT services (Technical Assistance Project, 2000). Underutilization can affect the lives of the children, 
especially with respect to the ease in which they can be integrated into home and community activities. In an effort to increase children's use of AT, the reauthorization of the Individuals with Disabilities Education Act (IDEA) (1997) required Individualized Education Program (IEP) and Individualized Family Service Plan (IFSP) teams to consider each student's need for AT and AT services at the time of plan development.

Assistive technology is any product that is used to increase, maintain, or improve the functional capabilities of individuals with disabilities. Examples include items as simple as a suction cup rattle as well as sophisticated computerized communication devices. Assistive technology services include the services and supports necessary to determine the appropriate technology to meet an individual's needs. Box 1 provides the legal definition of AT and AT services. This definition is used by service providers, policy-makers, and regulatory bodies. The continual advances in technology increase the likelihood that more and more infants and toddlers with disabilities could benefit from assistive devices.

Guidelines for selection of AT have been proposed to promote the appropriate consideration and use of AT. For example, one set of guidelines proposed that AT is deemed appropriate when the device (a) is related to specific and clearly defined goals that are meaningful to the child and family; (b) is compatible with practical constraints, such as funding resources; and (c) results in the child achieving desired outcomes (Judge \& Parette, 1998). In order to provide appropriate AT services, providers need the skills and knowledge to address competently

- AT needs and the services to support them,

- Strategies and funding mechanisms to pay for the needed technology and services,

- A strategy for measuring child and family outcomes, and

- Family and contextual factors such as culture, economic status, and geographical location and their impact on both attitudes toward and utilization of AT and AT services.

While requirements for $\mathrm{AT}$ and $\mathrm{AT}$ services have been legislated and guidelines for implementation have been proposed, there are still significant barriers to full utilization of AT and AT services. Some of these will be discussed below.

\section{TRAINING IN AT}

It is recognized that knowledge about AT and the services that support it is necessary to develop a comprehensive AT system; however, providers of services are not adequately

Box 1. Definition of Assistive Technology and Assistive Technology Services*

\section{Assistive Technology}

Any item, piece of equipment, or product, whether acquired commercially, off the shelf, modified, or customized, that is used to increase, maintain, or improve the functional capabilities of individuals with disabilities.

\section{Assistive Technology Services}

The evaluation of the needs of the child; purchasing, leasing, or otherwise acquiring a specific device; selecting, designing, fitting, customizing, adapting, applying, maintaining, repairing, or replacing specific devices; coordinating and using other services such as therapy, education, rehabilitation, and vocational training or technical assistance to the child, family, or caregivers in the use of specific devices; and technical assistance or training for professionals or others who provide services to the child.

${ }^{*}$ Technology-Related Assistance for Individuals with Disabilities Act (1988). 
trained to identify, design, use, and teach children, families, and other caregiving personnel to use assistive technology. Studies indicate that there is a shortage of professionals who are adequately or appropriately trained to provide AT or AT services to children (Lesar, 1998) or to serve children within an AT system of care. The need for more qualified service providers has also been recognized as well by families and children (Behrmann, 1995).

Postprofessional training in AT is available; however, professional training in AT appears to be limited. The Rehabilitation Engineering Society of North America (RESNA) offers a Fundamental Assistive Technology Program for any professional interested in becoming a certified Assistive Technology Professional (ATP). There are also several graduate programs throughout the country that concentrate on AT for children. These programs, however, are highly specialized, attract a specialized group of interested professionals, and have little impact on the more typical training of providers related to AT. Parette (1991) reported that $68 \%$ of respondents to an interdisciplinary survey had insufficient training during professional preparation regarding AT and its applications. A multistate study on the needs of school-based personnel indicated that $81 \%$ of providers feel their training needs in this area are not being met (Derer, Polsgrove, \& Reith, 1996).

Few programs are available to provide an integrated program of study related to AT. The federally funded Technical Assistance Projects (Tech Act Projects) are potential resources to address training; however, this training is usually device-specific. State Tech Act Projects offer a wide variety of courses related to various devices (University of Colorado Health Sciences Center, 1999; University of Kentucky, 2002). These projects have a great potential to enhance provider skills, but they currently lack the cohesiveness to impact the field broadly or to train "assistive technology specialists" who are available as resources within an AT system of care.

\section{DECISION-MAKING APPROACHES TO FOSTER USE OF AT}

Over the last decade providers of early intervention, especially physical and occupational therapists, have embraced the concept of clinical decision-making (Campbell, 1999) as a framework to design intervention plans for children with disabilities. There are several decision-making frameworks available to help the practitioner develop intervention plans. Traditionally, the choice of therapeutic intervention has been made using an impairment-oriented method of decisionmaking. In the impairment or deficit-oriented method, children are evaluated or assessed to determine impairments or to identify developmental skills that they do not perform. Treatments are then chosen that either remediate the impairment or facilitate the acquisition of the skill (Lahm \& Sizemore, 2002). When this approach does not remediate the impairment, nor promote skill acquisition leading to typical functioning, then the search begins for a device or system that compensates for the lack of skill (Campbell \& Forsyth, 1993; Kelligrew \& Alien, 1996).

Contemporary models of decisionmaking support an outcome-driven system (Campbell, 1999; Campbell \& Forsyth, 1993). In an outcome-driven system, intervention strategies are developed to promote the attainment of the desired outcome and maximize the skills of the individual (Cook \& Hussey, 2002). For example, the Hypothesis Oriented Algorithm for Clinicians (HOAC) (Rothstein \& Echternach, 1986) is a decisionmaking model used by physical therapists to guide treatment planning. HOAC is a 2-part procedure. Part 1 utilizes 8 steps to guide a therapist in deciding treatment options based on preestablished goals. Part 2 guides the therapist to reassess the appropriateness of the strategies chosen to meet the specific goal. In outcome-driven models compensatory strategies such as AT are not invoked only when remediation and facilitation strategies are unsuccessful, but are given equal priority in the treatment planning. 
Intervention strategies, including technology, are determined within the context of the task demand in an outcome-driven approach. Unfortunately, providers lack training in this model of decision-making and its relevance to AT and AT services (Campbell, 1999).

\section{CONTEMPORARY FUNDING CHALLENGES}

Service systems for children with disabilities are complex, involving multiple programs with differing eligibility criteria, different funding sources, and different purposes. Children within the same programs may have services funded by different payers (Bronheim, Magrab, \& Striffler, 1998). This complexity applies to AT services as well. Understanding the complexity of the services systems involved with children with disabilities and special health care needs is critical in making sound decisions that have a meaningful impact on the lives of children with disabilities and their families. Specifically, providers need the knowledge regarding funding to assure that AT-related plans can be implemented, yet many currently lack this knowledge and there are few training programs available that focus on these issues (Judge \& Parette, 1998). For example, many children who receive physical therapy are insured by Medicaid. Most children with disabilities and special health care needs receive physical therapy under IDEA. It is imperative that therapists understand the responsibilities of the Medicaid system, the early intervention system, and/or the educational system, and how these systems interrelate regarding funding of AT and AT services.

\section{KNOWLEDGE OF FAMILY CONTEXT AND NEEDS}

Providers must have knowledge and skills to understand the context within which AT will be used. This type of knowledge can only be obtained through input from consumers and families in planning the need, use, and benefits of AT (Parette \& Brotherson, 1996). The last 15 years have given rise to the ad- vent of person-centered and family-centered care for individuals with disabilities. Although many therapists share information with families and gather information from families, few collaborate equally with families in deciding treatment strategies, including AT, service delivery models, or necessary adjuncts to therapeutic intervention. Given the emphasis on family participation in early intervention it is imperative that providers consider family issues, concerns, needs, and preferences in making decisions regarding AT and AT services.

\section{KNOWLEDGE OF STRATEGIES TO ASSESS AT NEEDS}

The requirements of the IDEA have encouraged therapists and other providers of AT to examine the procedures specifically used to assess and determine AT needs of children. There are several assessment tools/strategies that are available to therapists to assist them in decision-making regarding AT. Table 1 provides salient information on 3 tools commonly used by AT professionals.

The use of these assessment approaches assists teams in making decisions on specific devices, strategies, or services once it is recognized that a specific AT device or AT service would be beneficial. Because of the complexity of AT and AT services, a broader framework is needed to ensure that these clientspecific models can be implemented and the information gathered can be used effectively. A model that outlines all the steps involved in the process will increase the likelihood that therapists and other early intervention providers will be comfortable in addressing the AT needs of the youngsters and planning appropriately to meet those needs.

\section{THE CONSORTIUM* MODEL}

The Consortium Model presented here is a 10-step procedure designed to guide

\footnotetext{
${ }^{*}$ The Consortium for Children and Youth with Disabilities and Special health Care Needs.
} 
Table 1. Assistive technology (AT) assessment models

\begin{tabular}{|c|c|c|}
\hline Name & Author & Purpose \\
\hline Education Tech Points & $\begin{array}{l}\text { Bowser and Reed } \\
\text { (1995) }\end{array}$ & $\begin{array}{l}\text { Questions related to AT used by professionals at } \\
\text { various points in the assessment process to } \\
\text { help teams effectively select AT and implement } \\
\text { AT services }\end{array}$ \\
\hline $\begin{array}{l}\text { The Student, the } \\
\text { Environment, the } \\
\text { Tasks, and the Tools } \\
\text { (SETT) }\end{array}$ & Zabala (1995) & $\begin{array}{l}\text { This is a collaborative process assisting teams in } \\
\text { building consensus regarding the child's need } \\
\text { for AT, the type needed, and the interventions } \\
\text { needed to support the AT }\end{array}$ \\
\hline $\begin{array}{l}\text { Matching Person and } \\
\text { Technology }\end{array}$ & $\begin{array}{l}\text { Institute for } \\
\text { Matching Person } \\
\text { and Technology } \\
\text { (2002) }\end{array}$ & $\begin{array}{l}\text { A user-driven and person-centered process used } \\
\text { to match individual with technologies. This is } \\
\text { actually a series of questionnaires that consider } \\
\text { the environment, the users' preferences, and } \\
\text { the functions and features of the AT }\end{array}$ \\
\hline $\begin{array}{l}\text { Human, Activity, } \\
\text { Assistive Technology } \\
\text { (HAAT) }\end{array}$ & $\begin{array}{l}\text { Cook and Hussey } \\
\text { (2002) }\end{array}$ & $\begin{array}{l}\text { The model takes into consideration the skills of } \\
\text { the individual, the task that the person is } \\
\text { expected to perform, and the context or } \\
\text { constraints on the activity }\end{array}$ \\
\hline
\end{tabular}

therapists through a series of actions and decisions regarding AT (see Fig 1) and addresses some of the barriers described earlier. Most providers are unprepared to participate fully in team decision-making regarding AT within early intervention or special education. This model operationalizes, for the provider, the specific steps needing decisions regarding AT and AT services and the information and personnel to be considered at each step (Table 2).

This model is based on the principles of outcome-driven decision-making and the belief that AT is a strategy to foster independence. Outcome-driven decision-making requires providers to make recommendations for AT and AT services based on what the family and team would like the child to accomplish within a set amount of time. To accomplish these outcomes, teams must design AT and AT service plans that address the barriers preventing achievement of the desired outcomes and the opportunities promoting the achievement of the outcomes in addition to remediating impairments.

As the developmental needs of the child change, providers must revisit the desired out- comes and reconsider a full range of intervention strategies and services. Contemporary practice promotes the use of AT as a strategy to increase independence and promote the acquisition of functional and developmental skills in addition to overcoming disabilities. This deviates from the traditional approach of using AT as a remediation effort. Identification of AT options and the integration of the technology into everyday activities is a time-consuming process requiring collaboration and cooperation among many people. Providers can facilitate collaboration and cooperation by understanding the process.

\section{Step 1: Recognition of a problem}

Family members, caregivers, or pediatricians are usually the first to recognize that an infant or toddler may be having difficulty in performing developmental tasks or functional activities and may refer the child to a developmental specialist or an early intervention program for a comprehensive evaluation to determine eligibility for services and the determination of type of services. 


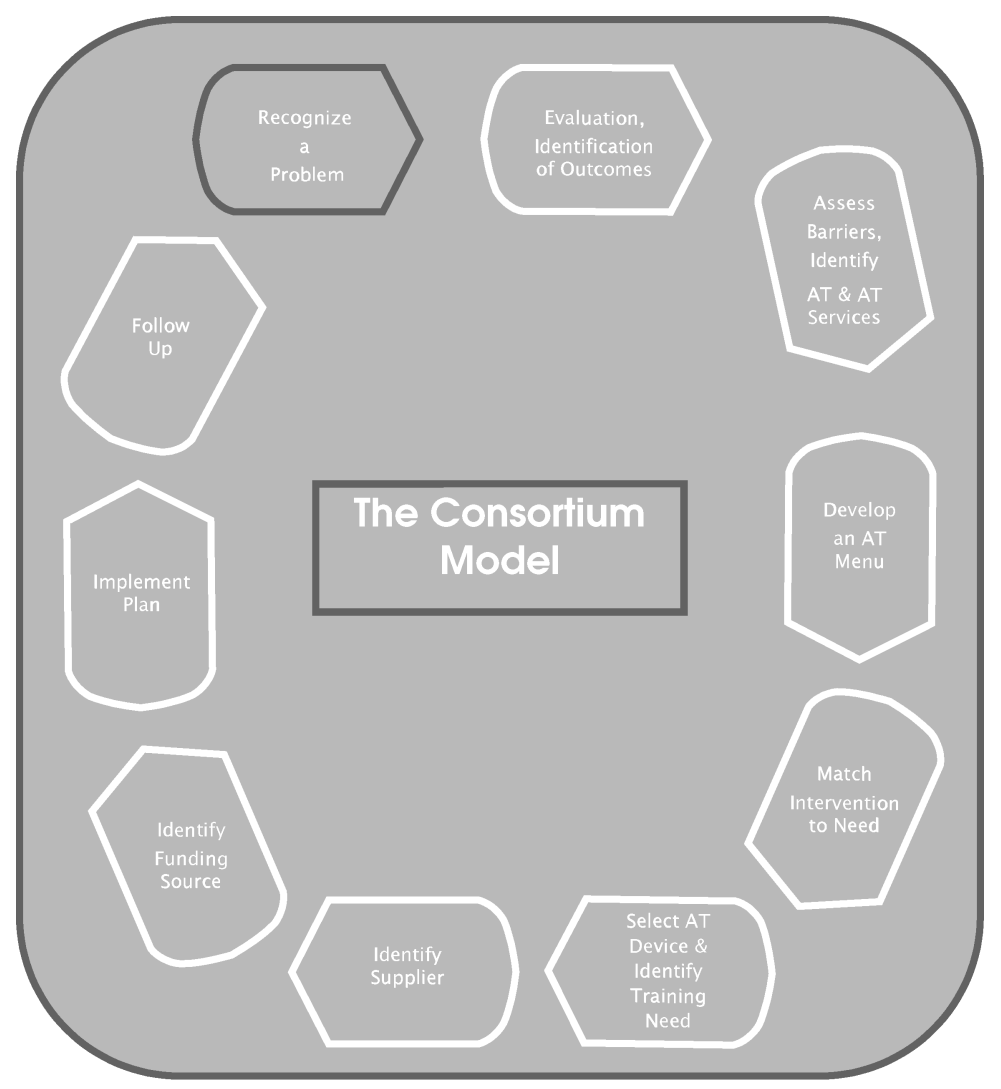

Fig 1. The Consortium Model.

\section{Step 2: Evaluation and outcome determination}

A comprehensive evaluation will delineate the overall developmental level of the child and provide a differential diagnosis if possible. In early intervention an IFSP will be developed with the family to determine familycentered outcomes and the services to meet those outcomes. Traditionally, services such as physical therapy or occupational therapy are identified and referrals are made to those providers to initiate intervention.

In an outcome-driven model the full range of services, which can facilitate the child's timely achievement of the desired outcomes, will be identified at this time. Because technology is benefiting younger and younger children, the evaluation of AT and AT services must be considered as a service to assist the child to meet the family-centered outcomes identified during the IFSP meeting. Assistive technology should be regarded as one of many strategies available to meet developmental and functional outcomes. The desired functional outcome, not the age or developmental level, will guide the team in deciding if AT or AT services would be appropriate.

\section{Step 3: Assessment/identification of $A T$ and $A T$ services}

There are technology options to assist a child in many activities: communication, mobility, positioning and seating, activities of daily living, recreation, and problem-solving. In a contemporary, outcome-driven decisionmaking approach AT and AT services are considered to be components of this planning step. It may be necessary to refer the child to experienced providers of AT as it is likely that the early intervention providers do not have 


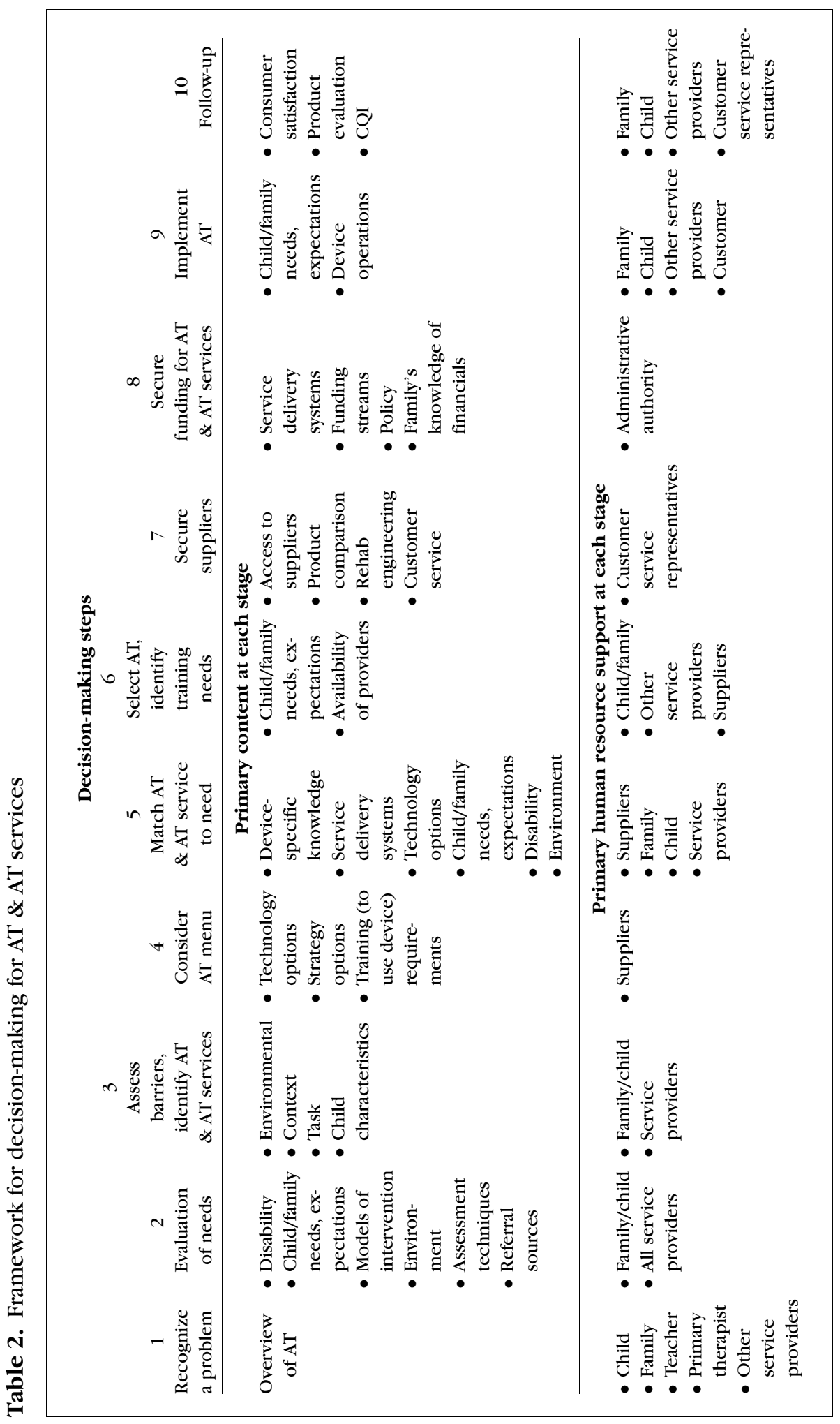


the skill to assess comprehensively AT needs. Community-based AT providers may include occupational therapists, physical therapists, special educators, speech-language pathologists, etc. There are also specialists, ATPs, who have been certified by the RESNA, who may be available to assist the team. Additionally, each state has a federally funded program, the Tech Act Project (www.ataporg.org) that is available to identify where AT assessment services can be found, if the local team feels ill prepared to conduct an assessment. At this step, however, it is imperative that the nonAT specialist provider be aware that AT and AT services are available and could be helpful in assisting the team in meeting the outcomes. As the outcome-driven model becomes more commonplace, providers will be forced to become more familiar with the variety of treatment options including AT and will develop collaborative relationships with communitybased AT providers.

At this point the AT specialists may augment existing data about the child's needs with data specific to AT by using one of the evaluation tools mentioned previously (see Table 1). For example, the SETT (Student, Environment, Task and Tools) provides a structure around which the child's current functional skills, the tasks the child wants/needs to accomplish, the environments in which the child would like/needs to participate in, and the tools (AT devices/services) that may be potentially useful can be discussed and documented (Zabala, 1995).

\section{Step 4: Develop an AT menu}

Assistive technology is any device used to increase, maintain, or improve functional abilities. Some devices are "low" tech and readily available at Toys " $R$ " Us, Wal-Mart, and other discount stores. Other "high" tech options are available through more specialized suppliers. Electronic communication, especially through the Internet, has greatly increased the availability of information about a whole array of AT products. For example, Abledata (www.abledata.com) is a national online database listing a wide variety of AT products. Prior to searching out specific de- vices, it is imperative that the team develops a list or menu of possible devices and services that would assist in promoting the outcomes developed. This menu will be used to match a specific device(s) to the child's individual needs and family circumstances.

\section{Step 5: Match AT and AT services to the child and family needs}

This step is often time-consuming. Prior to purchasing a device it is important to include a trial period with one or more products from the menu developed in Step 4. This trial period is critical in determining which product will best meet the child's individual needs and be accepted by the family. Some technologies may need to be used for a period of time before the team (including the child and family) can determine the actual usefulness of the tool. For some children it may be necessary to try a variety of devices or services. Each experience needs to be carefully evaluated with regard to the likelihood that the particular product will assist the child in accomplishing the outcome. There are several interrelated factors that must be considered in the selection of the device: child characteristics, family issues, the task and the context and environment in which it will take place, technology features, and service system issues. Ruling out a device during a trial period is a much more cost-effective step than abandoning a purchased product because it did not actually meet the child's need. Failure to take the time at this point will increase the likelihood of abandonment of the AT device. Abandonment of an AT device has been shown to (a) exacerbate the effects of the disability on the child, (b) increase financial burden on families, and (c) tax the limited resources of the service system (Parette, VanBiervliet, \& Hourcade, 2000). As part of an outcome-driven model, to determine the benefit of a device, it is important to assess the device within the environment that it will be used. It has been demonstrated that the recommendations on AT and AT services become more inadequate or inappropriate the further removed the assessment takes place from the environment in which the device is to be used 
(Behrmann \& Schepis, 1994). This approach increases the likelihood of abandonment.

\section{Step 6: Select a device and identify AT services}

Once all the options have been reviewed and undergone a trial period, the specific device is selected and the training needs of the child, family, and other care providers in relation to the device are outlined. The most common reason for abandonment of an AT device is lack of training on how to appropriately use the device and integrate it into everyday activities (Parette et al., 2000). A variety of people must be trained: child, family, other caregivers, teachers, etc. The importance of an individualized plan delineating the frequency of training for each trainee and the strategies that will be employed cannot be stressed enough. In order for the device to be useful, training must take place in naturally occurring activities and routines. It has also been shown that different audiences prefer differing methods of training. For example, Parette, Brotherson, Hourcade, and Bradley (1996) reported that families prefer to receive information and training from users of the technology, in particular, other families who have children with similar disabilities and AT experiences. They also prefer demonstrations and information tailored to their needs.

\section{Step 7: Identification of a supplier}

Although this step is closely aligned with Step 6, the decision on which supplier of a device will be chosen should be made following the selection of the device. Following a period of trial use, the team can make a recommendation for a specific product. As noted earlier, some products are readily available at local commercial retailers. A large number of mobility aids and feeding/eating aids can be found in children's stores or catalogues to address the needs of infants and toddlers. Frequently, these baby products (strollers, car seats, feeding dishes, etc) are significantly less expensive than similar products marketed as AT devices. Very often, minimal modifications can make a high chair or a Magic Marker very functional for a child with a disability.
For products which were designed specifically to meet the needs of children with a disability, sale and distribution may only be through specific suppliers. Suppliers should be knowledgeable in the advantages and disadvantages of a variety of devices, not just the devices they are authorized to sell and distribute. They should have a proven track record with working with therapists. Provider teams should develop collaborative relationships with a variety of vendors or suppliers of equipment. Oftentimes therapists or other care providers allow the vendor to influence decisions regarding types and features of AT because they feel unknowledgeable. It is important that AT selection is closely linked to the outcome that is desired. If decisionmaking is primarily left to the supplier there is the risk that the decision will be made solely on the availability of funding, the child's diagnosis, and the impairments of the child (Lahm \& Sizemore, 2002). Individual suppliers are often knowledgeable in a specific type of technology and thus, they may base decisions only on what they are familiar with and not the full range of products available (Lahm \& Sizemore, 2002). Lahm and Sizemore (2002) also note that finances often drive a supplier's choice of a device. In an outcome-driven decisionmaking model it is imperative that decisions are based on desired outcomes for the child.

Because many devices are highly sophisticated, careful attention should be given to vendors who also provide maintenance and teach caregivers basic maintenance and care for the equipment. No matter how successful the child is with a particular piece of technology, if the device is not in working order, it will not be useful to the child. Reliability and accessibility are 2 key features that a vendor of AT devices should possess.

\section{Step 8: Identify a funding source}

Funding can present a major barrier to accessing AT. There are 4 factors that impact identifying a funding source: (a) the high cost of the equipment, (b) vague or conflicting eligibility criteria imposed by funding sources, (c) professionals' lack of knowledge, and (d) difficulty accessing third party 
payment sources (Judge \& Parette, 1998). Although these present a great challenge, all too often funding issues are used to guide clinical decision-making. These are 2 separate issues. Funding is a matter of resource allocation. Outcome-driven decision-making focuses on what the child needs to complete successfully a specific task or outcome. When identifying the funding source, it is important to identify the cost of the product, and identify the costs associated with training. All too often devices are poorly integrated into a child's daily activities because of a lack of training and ongoing support for both the child and for other team members.

Many service providers immediately consider the "third party payment requirements," medical insurance, and school district or agency purchasing regulations, before a match between product and need has been made. When the issue is resource allocation, parents, families, and all team members should, initially, be educated on all the available technology options, and then decide how resources are best allocated to meet the child's needs. Resource allocation can include the family's decision to use private funds to purchase the product directly. In many situations, a discounted price and a much more timely delivery of the product can be arranged when private funds are being used for a "direct sale." In some instances, a cost-sharing model is used, using private medical insurance for a mobility aid for example. There are government funding programs, Medicaid for example, which will pay for "medically necessary" AT. If intended to meet a child's educational needs, the technology and related services need to be written into the child's IEP to secure district funding.

At least one member on the team needs to take the lead on identifying and securing funding. When resources, other than private funds, are being used, an understanding of the funding system's requirements is essential. A system of tracking paperwork, signatures, dates, and decisions made can prove to be invaluable as the request makes its way through the system. Each State's Tech Act Project may prove invaluable advocating for fund- ing and developing an information tracking system.

\section{Step 9: Implementation}

The process of identifying and selecting AT is extremely time-consuming. On the day a specific product is finally delivered, many on the team may feel they have reached the conclusion of the process. However, if the child is to be truly successful using the technology, the delivery day actually marks just the beginning. Ultimately, implementation should be the seamless use of the product by the child to complete the desired activities. To achieve this end, however, implementation must begin with training for the child and family on how to use the specific product. In some cases this training will be of fairly short duration, for example, instructing the family on how to fold a wheelchair for transportation in their car. Other training needs are slightly longer, eg, teaching mobility skills in both indoor and outdoor environments. Still others may involve initially intensive training with an ongoing need for support and modification, as the child's needs change, along with the increased use of and facility with the product, such as in the case of an augmentative communication system for expressive communication needs.

Teams using the outcome-driven approach should have clearly defined and measurable goals to monitor progress throughout the implementation phase. Teams who have invested the time and effort to clearly identify mutually agreeable outcomes, taken advantage of product trials, and outlined the training needs, should be able to monitor the child's progress toward attaining the expected outcomes. There will still be times when the device or the training will need to be modified to improve the outcome. However, clearly defined outcomes and careful follow-up and assessment of use of the product will provide the evidence that AT and AT services are benefiting the child.

\section{Step 10: Follow-up}

An essential element of any thorough intervention plan is follow-up or continuous 
quality improvement. To avoid negative consequences of using AT, the team must take the time to obtain continuous feedback from the technology users. Ongoing input from families and, as appropriate, the child, will decrease the likelihood of underutilization or abandonment. This process will also identify the successful use of the device or service, validating the team's original plan. Additionally, as the child successfully uses the technology other needs may become evident requiring adaptation of the device or additional training in its use. Although the child and family are the most important sources of information regarding the success of the AT and AT service, other team members may also provide important feedback. Assistive technology may help the child to be more integrated into the community, more independent, more curious, and more functional. As a result, care providers and therapists may need to tailor their interactions and/or treatment strategies to meet the child's changing needs or demands. They may need additional training or support to ensure appropriate utilization of the device. Additionally, ongoing information and feedback from the AT vendor and/or service representative should be sought. When the desired outcome is not achieved, the entire team should learn from the experience. Therapists and providers need to listen to and observe the child carefully to identify the issues that may be preventing a successful out- come. If the product is helping in accomplishing the task the child may use the product; conversely, if the product does not enable the child it will not be used.

\section{CONCLUSION}

An outcome-driven model of decisionmaking provides the opportunity for the family and service providers to design a plan of care using a variety of interventions to achieve the desired outcome. Assistive technology is a currently underutilized intervention by many providers. This article has described a model designed to assist provider teams in understanding the various decisionmaking steps to secure AT and AT services for young children with disabilities and special health care needs. Through collaboration among team members, children, and families, the identification, implementation, and utilization of AT devices and AT services may facilitate and promote attainment of specific functional outcomes for the children. Careful monitoring of progress toward the desired outcomes is essential throughout the process, which stresses trial use of products, identification of specific devices to meet the need, securing funding, and the immediate and ongoing training needs to facilitate seamless use of the technology to complete the functional activity.

\section{REFERENCES}

Behrmann, M. M. (1995). Assistive technology training. In K. F. Flippo, K. J. Inge, \& J. M. Barcus (Eds.), Assistive technology: A resource for school, work, and community (pp. 211-222). Baltimore: Brooks Publishing Co.

Behrmann, M. M., \& Schepis, M. (1994). Assistive technology assessment: A multiple case study review of three approaches with students with physical disabilities during the transition from school to work. Journal of Vocational Rebabilitation, 4(3), 202-210.

Bowser, G., \& Reed, P. (1995). Education TECH points for assistive technology planning. Journal of Special Education Technology, 12, 325-338.

Bronheim, S., Magrab, P., \& Striffler, N. (1998). Serving young children with special needs and their families in the community: A comparative analysis of federal opportunities and barriers. Washington, DC: Georgetown University Child Development Center.

Campbell, P. H., \& Forsyth, S. (1993). Integrated programming and movement disabilities. In M. Sneel (Ed.), Instruction of students with severe disabilities. (4th ed., pp. 751-811). Columbus, OH: Merrill.

Campbell, S. (1999). Models for decision making in pediatric neurologic physical therapy. In S. Campbell (Ed.), Decision-making in pediatric neurologic physical therapy. (pp. 1-22). New York: Churchill Livingstone.

Cook, A. M., \& Hussey, S. M. (2002). Assistive technologies: Principles and practice. St. Louis: Mosby.

Derer, K., Polsgrove, L., \& Reith, H. (1996). A survey 
of assistive technology: Applications on schools and recommendations for practice. Journal of Special Education Technology, 8, 62-80.

Individuals with Disabilities Education Act Reauthorization (1997). Washington, DC: US Government, Department of Education.

Institute for Matching Person and Technology. (1997). Matching person and technology. Retrieved February 23,2002 , from http://members.aol.com/IMPT97/ MPT.html.

Judge, S. L., \& Parette, H. P. (1998). Assistive technology decision-making strategies. In S. L. Judge \& $\mathrm{H}$. P. Parette (Eds.), Assistive technology for young children with disabilities: A guide to family-centered services (pp.127-147). Cambridge, MA: Brookline Books.

Kelligrew, D., \& Alien, D. (1996). Occupational therapy in full inclusion classrooms: A case study from the Moorpark Model. American Journal of Occupational Therapy, 50, 718-723.

Lahm, E. A., \& Sizemore, L. (2002). Factors that influence assistive technology decision-making. Journal of Special Education Technology, 17(1), 1-44.

Lesar, S. (1998). Use of assistive technology and young children with disabilities: Current status and training needs. Journal of Early Intervention, 21, 146-159.

Parette, H. P. (1991). Professionals working with people with disabilities: Technology training: Implications for teacher educators. Reston, VA. (ERIC Document Reproduction Service No. ED33679)

Parette, H. P., \& Brotherson, M. J. (1996). Family participation in assistive technology assessment for young children with disabilities. Education and Training in Mental retardation and Developmental Disabilities, 31(1), 29-43.

Parette, H. P., Brotherson, M. J., Hourcade, J. J., \& Bradley, R. H. (1996). Family-centered assistive technology assessment. Intervention in School and Clinic, 32(2), 104-112.

Parette, P., VanBiervliet, A., \& Hourcade, J. J. (2000). Family-centered decision-making in assistive technology. Journal of Special Education Technology, 15(1), 1-35.

Rothstein, J. M., \& Echternach, J. L. (1986). Hypothesisoriented algorithm for clinicians: A method for evaluation and treatment planning. Physical Therapy, 66, 1388-1394.

Technical Assistance Project. (2000). Update on the use of assistive technology among infants and toddlers. Library, TAP Bulletin. Available at: http://www. resna.org/taproject. Accessed: April 25, 2002.

Technology Related Assistance for Individuals with Disabilities Act, Pub. L. No. 100-407 (1988).

University of Colorado Health Science Center. Working with Colorado to develop assistive technology solutions. Retrieved October 22, 1999, from http://www.uchsc.edu/catp.

University of Kentucky. (2000). Quality indicators of assistive technology. Retrieved March 15, 2002, from http://www.qiat@lsu.uky.edu.

Zabala, J. (1995). The SETT framework: Critical issues to consider when making informed assistive technology decisions. Reston, VA. (ERIC Document Reproduction Services No. ED38196)

Lists of current articles: http:/ / depts.washington.edu/ isei/ iyc/ iyc_comments.html

To view previous articles:

http:/ / depts.washington.edu/ isei/ iyc/ iyc_previous.html 